\title{
MODELAGEM DA FORMAÇÃO DE POROSIDADES NA SOLIDIFICAÇÃO DE TARUGOS PELO PROGRAMA THERMO-CALC
}

\author{
Juliano Graziel Serra ' \\ Maurício Waineraich Scal ${ }^{2}$ \\ Flávio Ferreira ${ }^{3}$
}

\section{Resumo}

A porosidade é um dos defeitos mais comuns na produção de tarugos de LC de jato aberto. É motivo de expressivo sucateamento na laminação por trincas. Inúmeras causas são citadas na literatura como causadoras destes defeitos. Poucos trabalhos, no entanto, estudam sua formação a partir dos teores medidos dos gases hidrogênio, nitrogênio e oxigênio no aço líquido e dos valores estimados na frente de solidificação. É avaliada a influência de diversas variáveis de processo, sobretudo, as que influenciam o teor de hidrogênio no aço. São comparadas corridas com utilização de escórias sintéticas sinterizadas com escórias convencionais. É desenvolvido um modelo de previsão de formação de poros a partir da composição química e dos gases presentes, usando o programa Thermo-Calc. O modelo é confrontado com a literatura e com os dados obtidos experimentalmente. Os resultados são utilizados para tornar possível, em tempo real, ajustar o processo para evitar o aparecimento do defeito.

Palavras-chave: Solidificação; Porosidade; Gases; Thermo-Calc.

\section{POROSITY FORMATION MODEL DURING BILLET SOLIDIFICATION USING THERMO-CALC SOFTWARE}

\begin{abstract}
Blow and pin holes are the most common defects in open cast billet production. It is a cause of significant rolling mill scrap due to the incidence of cracks on end product. Many causes are pointed out as sources of these defects. However, few papers has studied their formation based on measured values of $\mathrm{H}, \mathrm{Ne} \mathrm{O}$ gases in liquid steel and estimated ones at solidification front. The influence of several process variables are investigated in this paper, mainly those factors related to the amount of $\mathrm{H}$ in steel. Heats using sintering synthetic slags and conventional slags are compared. It is developed a blow - pin holes prediction model based on the chemical composition and gases, through Thermo-calc program. The model results are compared to literature ones and experimental data. The Thermo-Calc results are used to be possible, in real time, adjust the process and avoid the appearance of these defects.
\end{abstract}

Key words: Solidification; Blow hole; Gases; Thermo-Calc.

\section{INTRODUÇÃO}

O processo de fusão e refino de uma aciaria elétrica utiliza intensamente gases como $\mathrm{O}_{2}$ e $\mathrm{N}_{2}$, expõe o aço líquido a atmosferas contendo $\mathrm{H}_{2} \mathrm{O}$ e $\mathrm{CO}+\mathrm{CO}_{2}$, que são gases formados no processo, bem como requer inúmeros insumos contendo hidrogênio e nitrogênio residuais, como o coque, ou de umidade $-\mathrm{H}_{2} \mathrm{O}$. Deste modo, é de se esperar que $\circ$ aço líquido tenha uma concentração significativa de elementos hidrogênio, nitrogênio, oxigênio e carbono, formadores de gases e que, durante a solidificação, devido à reduzida solubilidade dos mesmos no sólido, haja um natural enriquecimento no líquido remanescente, favorecendo a formação de poros e consequentemente, de defeitos no produto final.

O objetivo do presente trabalho é estudar a formação de porosidades superficiais (pin holes) ou porosidades internas (blow holes), que provocam desvios da qualidade e sucateamento de tarugos no lingotamento ou mesmo na laminação, devido à formação de trincas. Para isto investiga-se a influência dos elementos citados na formação de poros.

\footnotetext{
' Engenheiro Metalúrgico, M. Sc., Assessor Técnico de Processos, Gerdau Cosigua, Av. João XXIII, 6777, Distrito Industrial, Santa Cruz, Cep 23560-900, Rio de Janeiro, RJ, Brasil. E-mail: Juliano.Serra@gerdau.com.br

${ }^{2}$ Engenheiro Metalúrgico, M. Sc., Consultor Técnico, Gerdau Aços Longos S/A, Av. João XXIII, 6777, Distrito Industrial, Santa Cruz, Cep 23560-900, Rio de Janeiro, RJ, Brasil. E-mail: Mauricio.scal@gerdau.com.br

${ }^{3}$ Engenheiro Metalúrgico, Dr. Sc., Professor Adjunto, Universidade Federal Fluminense, Av. dos Trabalhadores, n. 420, Cep 27255-250, Volta Redonda, RJ, Brasil.E-mail: flavio@metal.eeimvr.uff.br
} 
Foram realizados experimentos industriais com ênfase nas variáveis que influenciam o teor de hidrogênio no aço, tais como: umidade relativa do ar, refrigeração dos eletrodos do forno elétrico e umidade da cal. Foram comparadas corridas com utilização de escórias sintéticas sinterizadas e de escórias convencionais. Para a realização dos cálculos termodinâmicos foi usado o software Thermo-Calc.

\section{I.I Formação de Porosidades nos Tarugos}

\section{I.I.I Caracterização}

Os poros são defeitos comuns na produção de tarugos de lingotamento contínuo de jato aberto.

Os poros superficiais (Figura I) apresentam formação de carepa na superfície interna e certa descarbonetação na matriz metálica ao redor do poro (Figura 2). A carepa impede $\circ$ caldeamento durante a laminação originando trincas.

Quando os poros superficiais apresentam uma profundidade acima da crítica e/ou os poros internos afloram à superfície, no forno de reaquecimento, há formação das trincas no produto laminado, conforme mostrado na Figura 2.

\section{I.I.2 Metalurgia da formação das porosidades}

A pressão crítica de um gás para que uma bolha se torne estável no aço líquido pode ser representada pela Equação $I^{(1)}$, onde $P_{A}$ é a pressão atmosférica, $P_{F}$ é a pressão ferrostática, $\sigma$ é a tensão superficial no ferro líquido e r é o diâmetro da bolha:
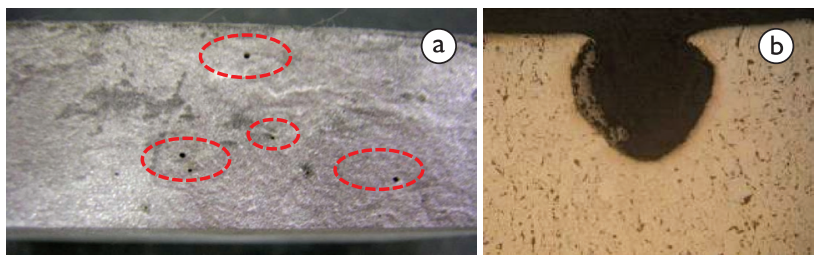

Figura I. a) Aspecto visual dos pin holes na superfície do tarugo após limpeza com jato de areia; b) Aspecto metalográfico dos pin holes. Ataque: Nital 2\%. Aumento: I00X.

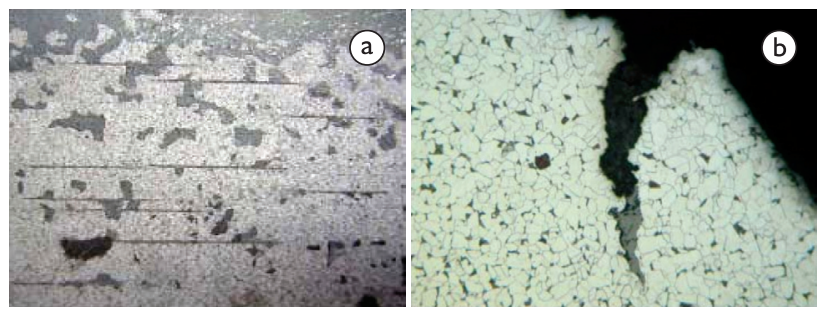

Figura 2. a) Aspecto das trincas superficiais de reduzida extensão e profundidade em uma barra laminada; b) Aspecto metalográfico das trincas de profundidade de $0,4 \mathrm{~mm}$ e carepa no interior. Ataque: Nital 2\%. Aumento: I00X.

$$
\mathrm{P}_{\text {Total }}=\mathrm{P}_{\mathrm{A}}+\mathrm{P}_{\mathrm{F}}+\frac{2 \sigma}{\mathrm{r}}
$$

Para uma bolha de gás de $1,0 \mathrm{~mm}$ de diâmetro, a pressão em excesso devido à tensão superficial é somente de 0,02 atm a 0,03 atm. Para o tamanho de porosidades observadas em lingotamento, o efeito da tensão superficial torna-se insignificante..$^{(2)}$

A formação de porosidades subsuperficiais em lingotamento contínuo ocorrerá nos primeiros estágios da solidificação, a uma pequena distância abaixo do menisco, onde a pressão total é levemente superior à pressão atmosférica. Deste modo, pode-se utilizar o valor de I,05 atm ${ }^{(3)}$, como pressão crítica para formação de blow holes

A pressão ferrostática cresce à medida que se afasta do menisco. Na saída do molde, a pressão ferrostática pode atingir $0,5 \mathrm{~atm}$. Por isso, é usual identificar porosidades no tarugo até uma pele de espessura de $10 \mathrm{~mm}-12 \mathrm{~mm}$, onde a pressão total já está próxima de I,5 atm.

Quando a soma das pressões parciais máximas de hidrogênio, nitrogênio e monóxido de carbono em equilíbrio com o aço líquido é maior que $\mathrm{P}_{\text {TOTAL }}$ (Equação 2), então podem ser formadas "bolhas" ou "poros".

$$
\mathrm{P}_{\text {gas }}^{\max }=\mathrm{P}_{\mathrm{H}_{2}}^{\max }+\mathrm{P}_{\mathrm{N}_{2}}^{\max }+\mathrm{P}_{\mathrm{CO}}^{\max }>\mathrm{P}_{\text {Total }}
$$

Junker e Kreuser ${ }^{(4)}$ realizaram experimentos com 14 corridas de aços de composições químicas similares com teores de carbono variando de $0,15 \%$ a $0,20 \%$, nitrogênio variando entre 80 ppm - 90 ppm, oxigênio na média de 20 ppm e hidrogênio, medido no lingotamento contínuo, variando de 4,5 ppm a $7 \mathrm{ppm}$. Todas as corridas apresentaram pressão máxima dos gases dissolvidos maiores que $\mathrm{I}, 0 \mathrm{~atm}$. Portanto, foram observadas porosidades em todos os casos. No entanto, só quando a pressão máxima se encontrava acima de I,5 atm, as porosidades causaram defeitos durante a laminação. $O$ diagrama típico obtido pelos autores está apresentado na Figura 3.

\section{I.I.3 Termodinâmica da formação das porosidades}

As equações termodinâmicas são necessárias para calcular a pressão parcial dos gases $\mathrm{H}_{2}, \mathrm{~N}_{2}$ e $\mathrm{CO}$ na frente de solidificação, a partir da concentração dos elementos no aço líquido. Gases diatômicos, como $\mathrm{H}_{2}$ e $\mathrm{N}_{2}$, dissolvem-se no aço líquido e ficam em equilíbrio com a fase gasosa, equacionado pela lei de Sievert - Equações 3 e 4.

$$
\begin{aligned}
& \frac{\mathrm{I}}{2} \mathrm{H}_{2}=\underline{\mathrm{H}} \\
& \mathrm{K}_{\mathrm{H}_{2}}=\frac{\mathrm{h}_{\underline{H}}}{\sqrt{\mathrm{P}_{\mathrm{H}_{2}}}} \\
& \mathrm{~h}_{\underline{H}}=\mathrm{f}_{\mathrm{H}} \times \% \mathrm{H} \\
& \text { In } \mathrm{K}_{\mathrm{H}}=-\frac{3770}{\mathrm{~T}}+5.334
\end{aligned}
$$




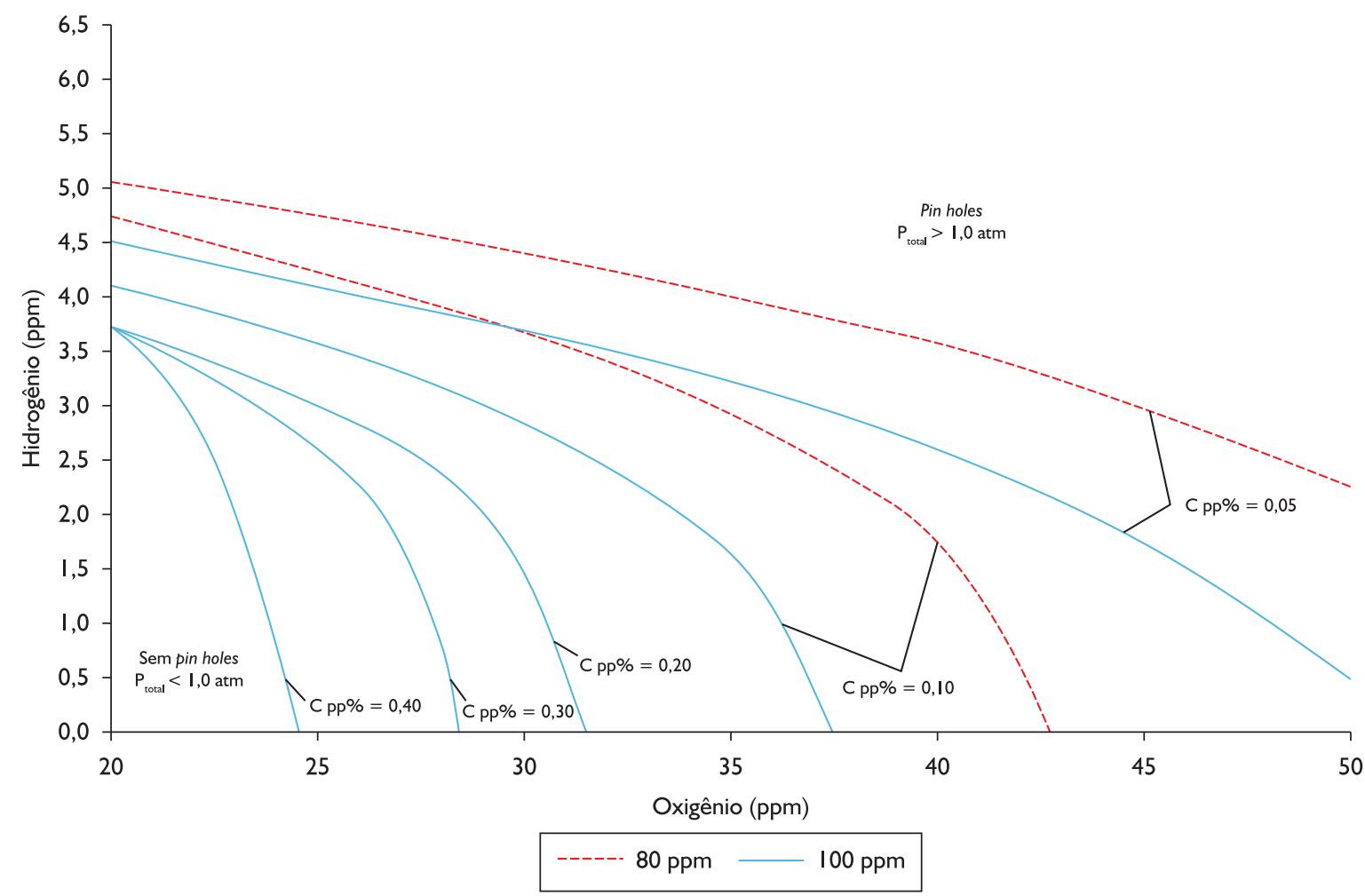

Figura 3. Diagrama de formação de porosidades ${ }^{4}$ em aços de vários teores de carbono, para teores de nitrogênio entre 80 ppm e 100 ppm, teores de oxigênio entre 20 ppm e 50 ppm e teor de hidrogênio até 6,5 ppm. ${ }^{4}$

$$
\begin{aligned}
& \frac{\mathrm{I}}{2} \mathrm{~N}_{2}=\underline{\mathrm{N}} \\
& \mathrm{K}_{\mathrm{N}_{2}}=\frac{\mathrm{h}_{\underline{N}}}{\sqrt{\mathrm{P}_{\mathrm{N}_{2}}}} \\
& \mathrm{~h}_{\underline{N}}=\mathrm{f}_{\underline{\mathrm{N}}} \times \% \mathrm{~N} \\
& \ln \mathrm{K}_{\mathrm{N}}=-\frac{433.2}{\mathrm{~T}}-2.870 \\
& \mathrm{CO}=\underline{\mathrm{C}}+\underline{\mathrm{O}} \\
& \mathrm{K}_{\mathrm{co}}=\frac{\underline{h}_{\mathrm{C}} \times \mathrm{h}_{\mathrm{O}}}{\mathrm{P}_{\mathrm{CO}}} \\
& \mathrm{h}_{\mathrm{c}}=\mathrm{f}_{\mathrm{c}} \times \% \mathrm{C} \\
& \mathrm{h}_{\mathrm{O}}=\mathrm{f}_{\mathrm{O}} \times \% \mathrm{O} \\
& \text { In } \mathrm{K}_{\mathrm{CO}}=\frac{2690}{\mathrm{~T}}+4.767
\end{aligned}
$$

A Figura 4 mostra que as solubilidades do hidrogênio e nitrogênio se reduzem ao passar do líquido para o sólido. Na transformação de fase $\mathrm{L} \rightarrow \delta$, a solubilidade máxima do nitrogênio cai de 450 ppm no líquido, para não mais que $120 \mathrm{ppm}$ no sólido $\delta$. Em $\gamma$, a solubilidade volta a crescer.

Pode-se então afirmar que os aços de baixo carbono, que têm expressiva fração de $\delta$ na transformação de fases, são críticos para a formação de porosidades.

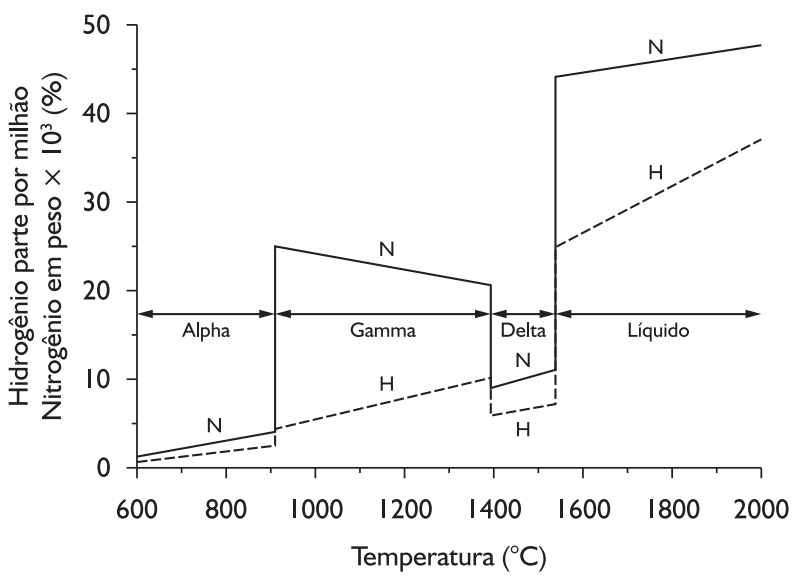

Figura 4. Solubilidades do $\mathrm{N}$ e do $\mathrm{H}$ no ferro para a faixa de temperatura de $600^{\circ} \mathrm{C}$ a $2.000^{\circ} \mathrm{C}$. $^{(7)}$

O soluto rejeitado pelo sólido enriquece o líquido remanescente na frente da solidificação. Essa concentração de hidrogênio e nitrogênio, fortemente aumentada, é utilizada para cálculo da pressão parcial máxima dos gases.

O carbono e o oxigênio apresentam o mesmo comportamento descrito. Tanto a concentração "enriquecida" de carbono quanto de oxigênio são utilizadas para a previsão da pressão parcial máxima de $\mathrm{CO}$. 
A Figura 5 mostra, esquematicamente, o processo de crescimento das dendritas na zona líquida-sólida. Com o crescimento da fração solidificada, há um enriquecimento progressivo de soluto no líquido remanescente retido entre os braços das dendritas. As porosidades surgem nesses pequenos volumes de líquido retido, onde a soma das pressões parciais dos gases pode superar 0 valor da $\mathrm{P}_{\text {total }}$.

O processo de transformação líquido $\rightarrow$ sólido de um aço está indicado na Figura 6. A solidificação inicia-se na temperatura $T_{L}$, com um líquido de composição $C_{0}$ e um sólido de composição $\mathrm{kC}_{0}$ ( $\mathrm{k}$ é o coeficiente de partição). $\mathrm{Na}$ temperatura $T^{\prime}<T_{L}$, a fração solidificada cresce e $\circ$ líquido enriquecido de soluto passa a ter a composição L'. Imediatamente antes da reação peritética $L+\mathrm{Fe} \delta \rightarrow \mathrm{Fe} \gamma$, a temperatura atinge $1.495^{\circ} \mathrm{C}$ e o teor de carbono no líquido alcança $0,5 \mathrm{I} \%$. Os modelos surgem para explicar a evolução da composição química do sólido e do líquido em função da fração solidificada $(\mathrm{g})$. Para $\mathrm{C}_{0}=0,20 \%$, a reação peritética ocorre com a fração solidificada $g=0,759$.

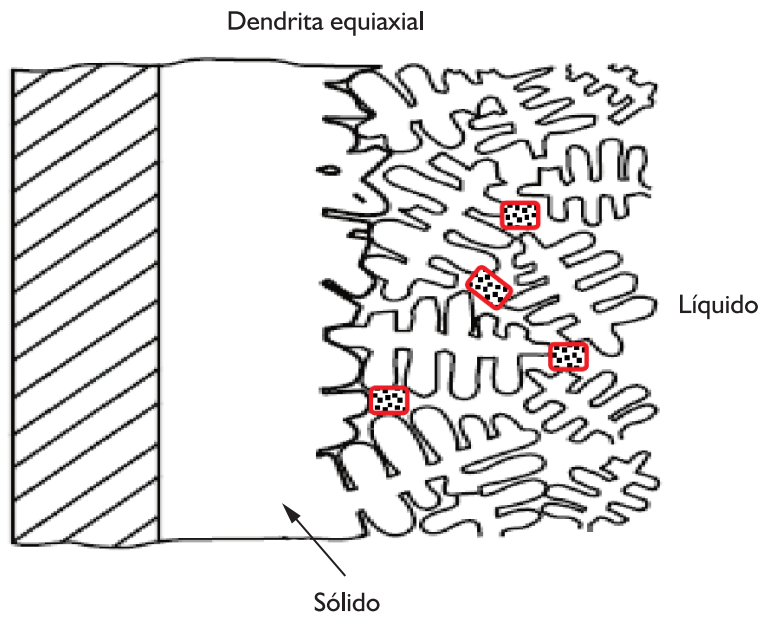

Figura 5. Crescimento de dendritas na região líquida - sólida.

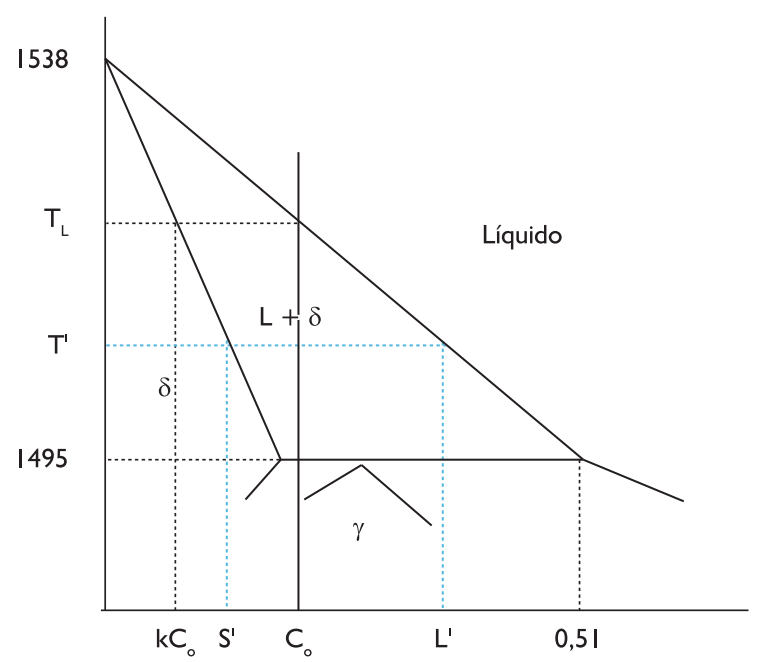

Figura 6. Representação esquemática do diagrama de transformação de fases da liga Fe-C.
O enriquecimento do soluto durante a solidificação do aço líquido é estimado pelo modelo proposto por Turkdogan, ${ }^{(8)}$ na década de 60.

O modelo considera que todos os elementos solutos estão completamente misturados nos pequenos volumes de líquido retido entre os braços das dendritas e suas concentrações crescem progressivamente durante a solidificação, conforme apresentado pela Equação 6. $\mathrm{C}_{0}$ é a concentração inicial uniforme do elemento em $\%$ em massa no líquido; $k$ é o coeficiente de partição do elemento entre o sólido $\mathrm{Fe} \delta$ ou $\mathrm{Fe} \gamma$ e o líquido e g representa a fração do líquido solidificado, na forma:

$$
\mathrm{Cl}=\frac{\mathrm{C}_{0}}{\mathrm{l}(\mathrm{l} \mathrm{k}) \mathrm{g}}
$$

O modelo de Turkdogan originalmente não leva em consideração a transformação de fase de $\mathrm{Fe} \delta$ para $\mathrm{Fe} \gamma$, quando o líquido solidifica, e é válido somente para aços de baixo carbono (\% $\mathrm{C}<0,15 \%)$.

O modelo proposto por Huang e $\mathrm{Liu}^{(6)}$ utiliza as mesmas equações para cálculo do enriquecimento do soluto adotadas por Turkdogan, mas incluindo a reação peritética, além de considerar o modelo de Scheil(9) para os elementos substitucionais silício e manganês.

O coeficiente de partição dos solutos é distinto para as reações $L \rightarrow \delta$ e $L \rightarrow \gamma$. Devido ao maior valor de $\mathrm{K}_{\mathrm{C}}, \mathrm{K}_{\mathrm{H}}$ e $\mathrm{K}_{\mathrm{N}}$ no Fe $\gamma$ do que no $\mathrm{Fe} \delta$, as concentrações ou pressões parciais desses elementos atingem um valor máximo na reação peritética.

Não se deve esperar uma diferença tão significativa nos teores de oxigênio após a reação peritética. Os coeficientes de partição do oxigênio são similares nas fases $\delta$ e $\gamma$. Como são os mais baixos entre os demais elementos, é uma indicação da menor solubilidade em qualquer uma das fases e uma tendência de maior segregação no líquido remanescente.

Diferentemente do hidrogênio e nitrogênio, a concentração de oxigênio não pode crescer livremente. Os elementos desoxidantes silício, manganês e alumínio, presentes no aço líquido, reagem com o oxigênio formando óxidos e representam um "freio" ao crescimento do oxigênio. A previsão acurada do oxigênio é um das maiores dificuldades do modelo.

\section{I.I.4 Fontes de $\mathbf{H}$ no processo de fabricação}

Em aços com reduzida carburação na panela, a absorção de hidrogênio pelo aço é fundamentalmente devida à umidade (Figura 7). Utilizando a reação de dissociação do vapor da água e sua constante de equilíbrio podem ser obtidos, diversos diagramas de equilíbrio:

$$
\begin{aligned}
& \mathrm{H}_{2} \mathrm{O}(\mathrm{g})=2 \underline{\mathrm{H}}+\underline{\mathrm{O}} \\
& \mathrm{K}=\frac{[\mathrm{ppmH}]^{2} \times[\mathrm{ppmO}]}{\mathrm{P}_{\mathrm{H}_{2} \mathrm{O}}(\mathrm{atm})}=1,77 \times 10^{6} \text { a } 1.600^{\circ} \mathrm{C}
\end{aligned}
$$


Alguns conceitos relevantes podem ser destacados na Figura 9. Quando os teores de oxigênio são muito elevados, a solubilidade do hidrogênio é muito limitada. Deve-se esperar, portanto, que a absorção do hidrogênio no Forno elétrico a arco - FEA, com 600 ppm a 1.000 ppm de oxigênio seja significativamente menor que no forno panela - FP com 20 ppm a 50 ppm de oxigênio Ao crescer a pressão parcial de $\mathrm{H}_{2} \mathrm{O}$, a solubilidade do hidrogênio também cresce. É de se esperar que, em períodos chuvosos (verão) haja um maior teor de hidrogênio no aço que em períodos secos (inverno) ${ }^{(10)}$ e que haja uma correlação entre o hidrogênio e a umidade absoluta do ar, conforme apresentado na Figura 8.

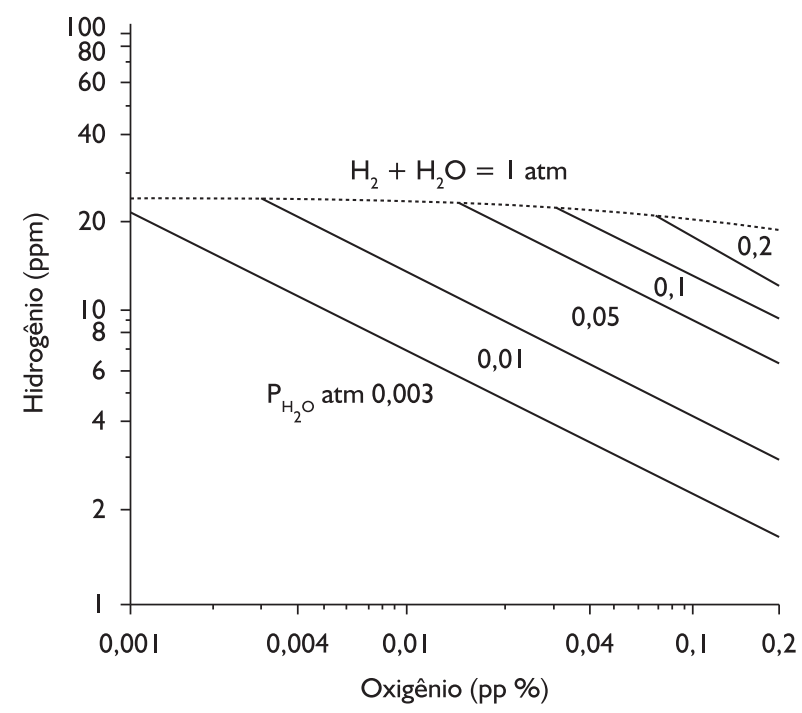

Figura 7. Concentração de hidrogênio e oxigênio no ferro líquido a $1.600^{\circ} \mathrm{C}$, em equilíbrio com as composições indicadas das misturas $\mathrm{H}_{2}-\mathrm{H}_{2} \mathrm{O} \cdot{ }^{(8)}$

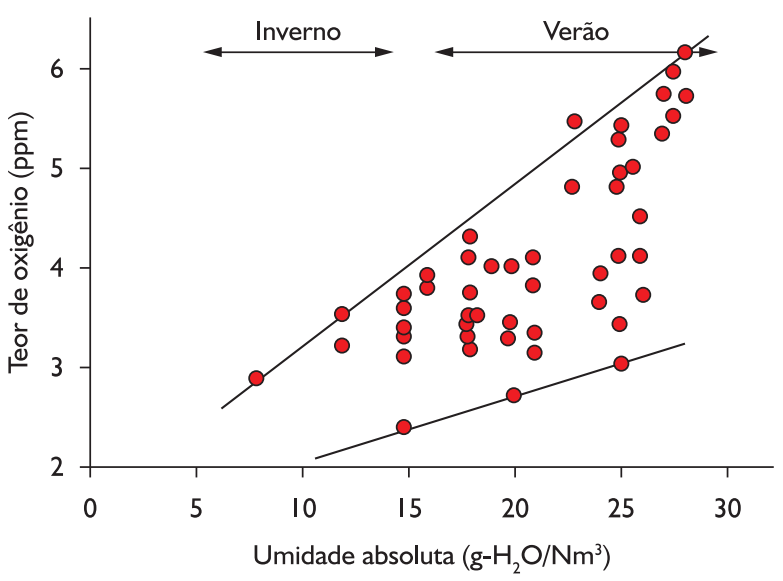

Figura 8. Teor de hidrogênio em função da umidade absoluta do ar no inverno e no verão. ${ }^{(10)}$

\section{I.I.4.I Absorção de hidrogênio no forno elétrico}

Água na forma de vapor no ar ou na forma líquida na sucata, cales, carburantes e refrigeração de eletrodos são as principais fontes de hidrogênio no forno elétrico. $A$ basicidade da escória e seu nível de oxidação contribuem também para $\mathrm{o}$ aumento da absorção de hidrogênio. ${ }^{(10)} \mathrm{A}$ absorção é minimizada devido as bolhas de $\mathrm{CO}$, formadas no processo, arrastarem para fora consideráveis quantidades de hidrogênio. ${ }^{(1)}$

A escória do FEA pode ser uma fonte significativa de hidrogênio para o aço. As reações 7 e 8 sugerem crescimento contínuo do teor de $\mathrm{OH}$-, enquanto existir uma fonte de hidrogênio e íons de oxigênio livres na escória.

$$
\underline{\mathrm{H}}+\underline{\mathrm{O}} \rightarrow \underline{\mathrm{OH}}(\text { escória })
$$

$$
\mathrm{H}_{2} \mathrm{O}(\mathrm{g})+\underline{\mathrm{O}}(\text { escória }) \rightarrow \underline{2 \mathrm{OH}}(\text { escória })
$$

Durante a transferência do aço do forno para a panela, dois importantes fatores influenciam na absorção de hidrogênio. $O$ primeiro fator é que se adiciona a maior quantidade de ligas e desoxidantes no vazamento. Uma vez que $\circ$ aço fica desoxidado, a solubilidade de hidrogênio aumenta sensivelmente. ${ }^{(5)} O$ segundo e controlável fator é a passagem de escória do forno para a panela. A escória que está sobre o aço começará a entrar em equilíbrio, representada pela reação 9 , e liberará também hidrogênio para $\circ$ aço.

$$
\underline{\mathrm{OH}}(\text { escória }) \rightarrow \underline{\mathrm{O}}(\text { escória })+\underline{\mathrm{H}}(\text { aço })
$$

\section{I.I.4.2 Absorção de hidrogênio do forno panela}

A cal adicionada para o ajuste da composição química das escórias da panela é um das maiores fontes de hidrogênio para $\circ$ aço. Experimentos ${ }^{(12)}$ executados em laboratório investigaram o efeito da cal hidratada - $\mathrm{Ca}(\mathrm{OH})_{2}$ - nos teores de hidrogênio de aços carbono (Figura 9).

O $\mathrm{CaO}$ é altamente higroscópico e pode formar hidróxido de cálcio. As condições climáticas podem exasperar essa situação. Quando em contato com o aço líquido decompõe-se e libera hidrogênio para o mesmo. A utilização de escórias sintéticas ao invés da cal torna-se uma alternativa atrativa para reduzir a absorção de hidrogênio no Forno Panela. ${ }^{(13)}$

\section{I.I.4.3 Absorção de hidrogênio do lingotamento contínuo}

A umidade da palha de arroz e presente no óleo de lubrificação dos moldes são as principais fontes de hidrogênio para o aço, sobretudo pelo aço estar desoxidado nessa etapa. 


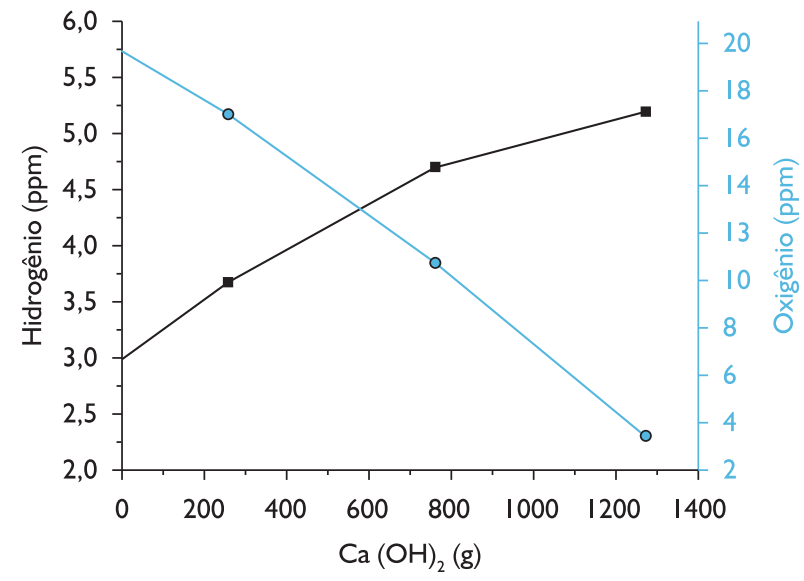

Figura 9. Absorção de hidrogênio devido a adição de $\mathrm{Ca}(\mathrm{OH})_{2}$ na escória. ${ }^{(12)}$

Apesar de ser um desvio do processo, a secagem inadequada dos refratários do distribuidor é responsável pela desclassificação importante de tarugos. ${ }^{(5)}$

O uso de óleos lubrificantes no molde do lingotamento contínuo, mesmo isentos de umidade, já é considerado um fator favorável à formação de porosidades. Por efeito das elevadas temperaturas na região do menisco, há uma decomposição do óleo lubrificante gerando carbono, que é o lubrificante sólido e vapores do óleo. Há um aporte de hidrogênio, porém a literatura não é conclusiva quanto à contribuição para a formação de pin holes. ${ }^{(5)}$

\section{MATERIAL E MÉTODOS}

Todos os experimentos foram realizados em escala industrial. As composições químicas das corridas, inclusive carbono e nitrogênio, foram determinadas por um espectrômetro de emissão ótica ARL modelo 3460. O teor de oxigênio dissolvido no aço foi determinado pelo método Celox. ${ }^{(14)} \bigcirc$ equipamento de medição direta de hidrogênio HYDRIS ${ }^{(12)}$ foi utilizado para determinar o teor de hidrogênio.

Todas as medições foram realizadas no distribuidor da máquina de Lingotamento Contínuo no instante em que $50 \%$ da corrida já havia sido lingotada, minimizando o efeito de misturas.

Foi utilizada selagem gasosa no molde a fim de reduzir a reoxidação do aço. Foi adicionado ainda alumínio em fio diretamente no jato de aço no interior do molde para realizar uma desoxidação complementar. Com essa prática estima-se obter uma redução dos teores de oxigênio em relação à última medição que ocorre no distribuidor. Acredita-se que é possível reduzir o teor de oxigênio do aço para um valor entre 10 ppm a 15 ppm.

Foram avaliadas diversas condições operacionais para verificar a influência nos teores de hidrogênio, nitrogênio oxigênio e carbono, o impacto na pressão parcial dos gases e, consequentemente, na formação de porosidades nos tarugos (Tabela I). Dentro dos limites da prática industrial, procurou-se minimizar as variações dos parâmetros não avaliados.

Tabela I. Condições operacionais avaliadas

\begin{tabular}{clc}
\hline Condição & \multicolumn{1}{c}{ Descrição } & Corridas \\
\hline I & $\begin{array}{l}\text { Corridas produzidas com a prática usual de } \\
\text { formação da escória na panela com cal e } \\
\text { fluorita. }\end{array}$ & 70 \\
\hline 2 & $\begin{array}{l}\text { Corridas produzidas com a prática modi- } \\
\text { ficada de formação da escória na pan- } \\
\text { ela substituindo a cal e fluorita por escória } \\
\text { pré-sinterizada. }\end{array}$ \\
\hline 3 & $\begin{array}{l}\text { Idem à condição I com alteração na vazão } \\
\text { de água de refrigeração dos eletrodos de } \\
25 \text { L/min para 20 L/min }\end{array}$ \\
\hline 4 & $\begin{array}{l}\text { Idem à condição I, com monitoração da } \\
\text { umidade relativa do ar }\end{array}$ & 18 \\
\hline 5 & $\begin{array}{l}\text { Idem à condição 2, com monitoração da } \\
\text { umidade relativa do ar. }\end{array}$ & 15 \\
\hline
\end{tabular}

Foram realizadas contagens de porosidades - pin holes e blow holes - em todas as corridas utilizadas no experimento utilizando técnicas convencionais. Para contagem de blow holes, a inspeção visual é realizada na seção transversal da amostra. Para contagem de pin holes, a inspeção visual é realizada na superfície da amostra, após remoção da carepa por jato de granalha. $O$ resultado final é a soma da quantidade encontrada $n$ nas quatro faces $e$ expressa em $\mathrm{n} / \mathrm{m}^{2}$. Em casos específicos, foram realizadas análises metalográficas em microscópio ótico Zeiss axiotech e em microscópio eletrônico de varredura Zeiss DSM 962 acoplado ao sistema EDS (Energy Dispersive Spectroscopy), que permitem identificar os elementos presentes nas inclusões.

$\mathrm{Na}$ modelagem do cálculo das pressões parciais dos gases foi utilizado o programa termodinâmico Thermo-Calc versão M. O modelo as calcula considerando o enriquecimento de soluto na frente de solidificação e utiliza como dados de entrada os valores medidos nos experimentos realizados. A elaboração do modelo propriamente dito será objeto de outro trabalho da $\mathrm{ABM}$. Os resultados são comparados com os modelados por Huang e Liu. ${ }^{(6)}$

\section{RESULTADOS E DISCUSSÃO}

\section{I Experimentos em Escala Industrial}

Comparando os resultados da Tabela 2, observa-se que, utilizando escória sintética (condição 2), os teores de hidrogênio reduzem-se significativamente. O máximo da condição 2 é inferior à média da condição $\mathrm{I}$. 
Tabela 2. Valores de hidrogênio e nitrogênio e oxigênio obtidos nos experimentos com as condições I (escória comum) e 2 (escória présinterizada). Valor do Limite Inferior de Controle (LIC) e Limite Superior de Controle (LSC) obtidos na carta de controle

\begin{tabular}{lcccc}
\hline Elemento & Condição & Média & LIC & LSC \\
\hline \multirow{2}{*}{ Teor de H } & I & 6,0 & 4,9 & 7,7 \\
& 2 & 5,0 & 4,2 & 5,8 \\
\hline \multirow{2}{*}{ Teor de N } & 1 & 73 & 32 & 114 \\
& 2 & 70 & 39 & 101 \\
\hline \multirow{2}{*}{ Teor de O } & I & 25,6 & 18,1 & 33,0 \\
& 2 & 22,2 & 15,8 & 28,6 \\
\hline
\end{tabular}

Provavelmente, esta diferença está associada à umidade presente na cal e na fluorita utilizada no processo de fabricação dos aços e que pode variar de $0,5 \%$ a $4,5 \%$. Como citado anteriormente, a escória sintética apresenta elevada resistência à absorção de umidade pelo fato deste produto passar por um processo de sinterização durante sua fabricação. Assim, os valores de umidade deste material estão abaixo de $0,3 \%$. $^{(14)}$

Já o teor de nitrogênio está semelhante nas duas condições, visto que nenhuma modificação no processo foi realizada a fim de alterar esta condição.

O teor de oxigênio não apresenta variações significativas.

Quando se variou a vazão de água de refrigeração dos eletrodos do forno elétrico (Figura I0), não foi possível perceber mudanças significativas nos teores de hidrogênio das corridas. Provavelmente, grande parte da água de refrigeração dos eletrodos do forno elétrico evapora antes mesmo de entrar em contato com a escória do forno. $\mathrm{O}$ hidrogênio resultante da parcela de água dissociada na escória é retirado pelas bolhas de $\mathrm{CO}$ formadas durante a fusão ou pela escória, que é removida do forno elétrico durante $\circ$ processo de fabricação. A quantidade limitada de escória que passa para a panela no vazamento é mais um fator que contribuiu para este resultado.

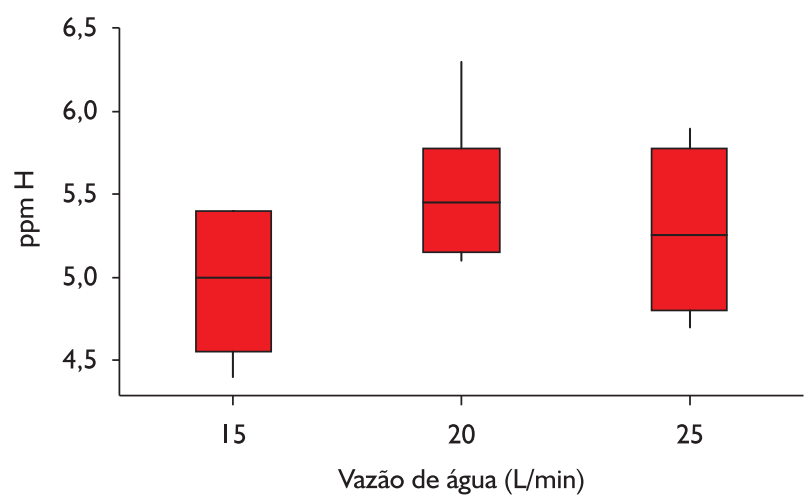

Figura 10. Teores de hidrogênio para diferentes vazões de água de refrigeração dos eletrodos do forno elétrico para a condição 3 .
A umidade relativa do ar não apresenta correlação significativa com o teor de hidrogênio, em ambas as condições testadas (Figura II), ainda que a dispersão das corridas da condição 5 tenha sido ligeiramente reduzida. Como a cal é higroscópica e a escória sinterizada não, o aumento da umidade do ar afeta apenas a escória à base de cal - fluorita.

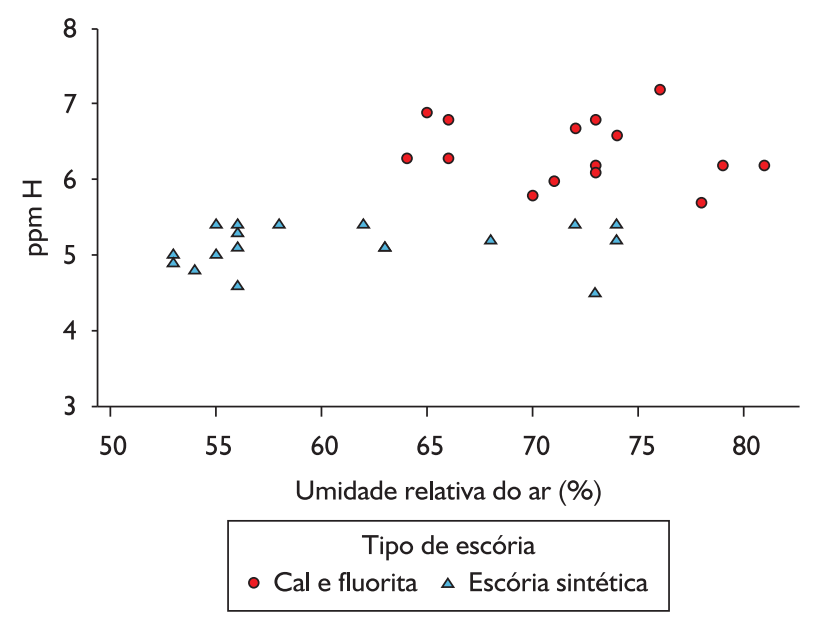

Figura I I. Teores de hidrogênio para diferentes umidades relativas do ar nas condições 5 e 6 .

\subsection{Validação do Modelo a partir do Software Thermo-calc}

Na Figura 12 podem ser observados os resultados da pressão máxima obtidas a partir da simulação no software Thermo-Calc. Os resultados obtidos apresentam boa concordância com os de Huang e Liu' no cálculo da pressão máxima dos gases $-P_{\text {gas }}^{\max }=P_{\mathrm{H}_{2}}+P_{\mathrm{N}_{2}}+\mathrm{P}_{\mathrm{CO}}-\mathrm{em}$ função da fração solidificada (Figura 13). Ambos preveem que a pressão máxima alcança cerca de I,75 atm na mesma fração solidificada.

A diferença entre as curvas é decorrente das diferenças na previsão de $P_{c o}$, sobretudo no teor de oxigênio. Nestes cálculos, considera-se o valor de oxigênio igual a 10 ppm; já o modelo de referência não menciona o teor de oxigênio utilizado no cálculo da pressão total.

Deve ser ressaltado que, durante o processo de solidificação, com aumento do teor de oxigênio e, em menor escala, o silício no líquido remanescente, proporcionam-se as condições necessárias para reação de desoxidação, por exemplo, $\mathrm{Si}+2 \mathrm{O}=\mathrm{SiO}_{2}$.

Esta reação controla $\circ$ ter de oxigênio na frente de solidificação e, consequentemente, evita que a pressão parcial de $\mathrm{O}_{2}$ atinja valores ainda maiores servindo, portanto, como freio para formação de poros. Deste modo, a presença significativa de elementos desoxidantes - neste caso, o silício - deve ser usada para evitar a formação de porosidades. 


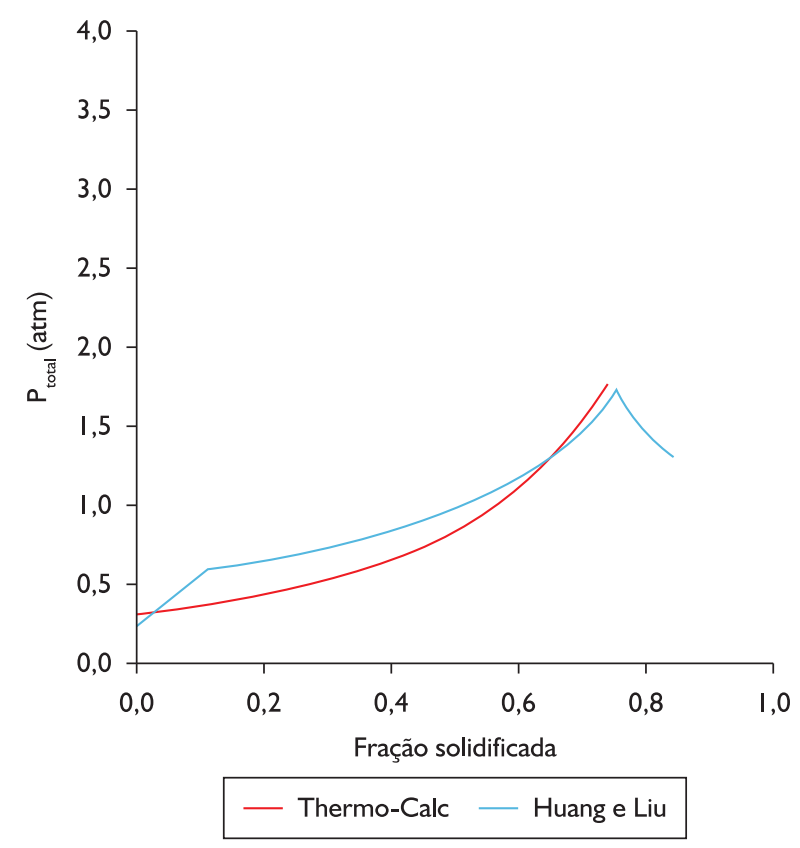

Figura I2. Pressão total para um aço com $\mathrm{C}=0,2 \%, \mathrm{Si}=0,25 \%$, $\mathrm{H}=9 \mathrm{ppm}, \mathrm{N}=80 \mathrm{ppm}$ e $\mathrm{O}=10 \mathrm{ppm}$, obtido pelos dois modelos de cálculo.

O modelo de desoxidação ainda pode ser aprimorado incorporando o efeito relevante de teores residuais de alumínio. ${ }^{(15)}$ No entanto, considerando apenas a formação de sílica pura como produto da desoxidação, tem-se:

$$
\begin{aligned}
& \text { In } \mathrm{K}_{\mathrm{Si}}=\frac{70034}{\mathrm{~T}}-26,69 \\
& \mathrm{~K}_{\mathrm{Si}}=\frac{\mathrm{I}}{\mathrm{a}_{\mathrm{Si}} \times \mathrm{a}_{0}^{2}} \\
& \mathrm{a}_{\mathrm{Si}}=\mathrm{f}_{\mathrm{Si}} \times \% \mathrm{Si}
\end{aligned}
$$

Lei de Henry

$$
\begin{aligned}
& \log \mathrm{f}_{\mathrm{Si}}=\sum \mathrm{e}_{\mathrm{Si}}^{\mathrm{j}} \times \% \mathrm{j} \\
& \text { Equação de Wagner }
\end{aligned}
$$

Para a temperatura de $1.495^{\circ} \mathrm{C}$, a constante de equilíbrio da reação $-\mathrm{K}_{\mathrm{Si}}$ é $4,09 \mathrm{E}+05^{5}$. Portanto, para uma composição típica do aço deste trabalho, e utilizando o valor de $\mathrm{f}_{\mathrm{si}}=1,75^{5}$, é possível calcular os teores de oxigênio em equilíbrio com o silício. Teores de silício. inferiores a $0,18 \%$ permitem que o aço tenha teores máximos de oxigênio dissolvido superiores a $28 \mathrm{ppm}^{5}$ no molde. Esta é uma das justificativas para a dificuldade de se obter tarugos isentos de porosidades em aços de baixos teores de silício.

A presença de teores residuais de alumínio praticamente torna desprezível a quantidade disponível de oxigênio. Um teor de alumínio dissolvido de 10 ppm assegura menos de 7,0 ppm de oxigênio dissolvido no molde.
Este fato justifica a manutenção da injeção de alumínio no molde a despeito de todos os inconvenientes observados na prática operacional, sobretudo, o aumento do índice de perfurações.

No lingotamento de jato aberto, o aço líquido, ao passar do distribuidor para o molde, arrasta ar consigo. Szekely ${ }^{(16)}$ mostra exemplos de incorporação de oxigênio de mais de 10 ppm que é da mesma ordem de grandeza dos teores de oxigênio obtidos com a desoxidação intensiva no molde.

Este fato confirma a importância da proteção gasosa no distribuidor - molde com respeito à redução do índice de porosidades, não só por minimizar o arraste de ar, como também, para evitar a oxidação do alumínio residual presente no aço.

\subsection{Cálculo da Pressão Total dos Gases a partir dos Dados Experimentais}

O modelo desenvolvido é aplicado às condições reais de produção, baseando-se nos valores de carbono, silício, manganês, oxigênio, nitrogênio e hidrogênio, medidos em cada corrida. Utilizam-se as combinações de média, mínimo e máximo de cada elemento, de modo que os cálculos da pressão abrangessem o maior número possível de possibilidades reais. As corridas selecionadas pertenciam às condições de processo I e 2, já descritas anteriormente.

Praticamente todas as corridas apresentam pressão total superior a I,05 atm, que é a pressão a partir da qual os poros começam a ser formados; ${ }^{(3)}$ porém, $71 \%$ das corridas da condição I e $29 \%$ das corridas da condição 2 apresentam $P_{\text {total }} \geq I, 2 \mathrm{~atm}$. Somente a condição I apresenta corridas com $P_{\text {total }} \geq 1,5 \mathrm{~atm}$.

Segundo Junker e Kreuser, ${ }^{(4)}$ poros superficiais não causam problemas nos produtos finais e nem durante 0 lingotamento quando a pressão total for abaixo de I,2 atm, pois os poros estão em pequenas quantidades e tamanhos reduzidos. Entre 1,2 e 1,5 atm, os poros começam a ser um fator de risco para o produto final, e alguns defeitos começam a serem observados, porém sem comprometer o produto final. A partir de I,5 atm, os poros aumentam em quantidade e tamanho e se tornam críticos, causando o sucateamento de produtos nas laminações.

As diferenças esperadas de desempenho nas laminações, quando se comparam as condições I e 2 , se confirmaram. A I a apresentou um sucateamento de $2,0 \mathrm{~kg} / \mathrm{t}$, enquanto que na $2^{\mathrm{a}}$, utilizando escória sintética, o valor reduziu-se drasticamente para $0,16 \mathrm{~kg} / \mathrm{t}$. Isto corresponde a uma redução de $92 \%$ na incidência de porosidades críticas nos tarugos, superior ao esperado pela diferença das pressões totais dos gases.

A diferença básica entre as condições I e 2 é a utilização de escória sintética, que traz o benefício de reduzir significativamente $o$ teor de hidrogênio. 
Uma alteração de processo tão simples provoca uma mudança significativa no desempenho dos tarugos na laminação. Este resultado mostra que é um risco usar cal armazenada em silos convencionais na formação de escórias na panela. Por falhas de controle do estoque e/ ou condições climáticas desfavoráveis a cal pode hidratar durante a armazenagem e as análises dos insumos não detectam essa alteração da qualidade, aumentando significativamente a chance de ocorrência de poros nos tarugos.

A Figura 13 mostra que há uma tendência de aumento do número de poros com o aumento de $\mathrm{P}_{\text {total }}$. No entanto, a correlação é fraca.

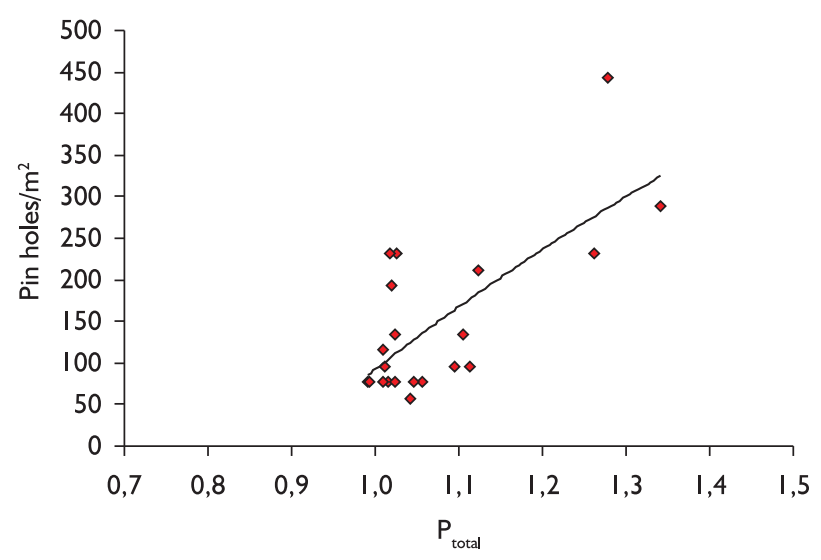

Figura 13. Correlação entre pressão total e número de pin holes por $\mathrm{m}^{2}$.

\subsection{Diagrama de Domínio Crítico para Formação de Poros}

Calculando-se a pressão total a partir dos elementos químicos relevantes e usando o critério de $P_{\text {total }} \geq 1,2 \mathrm{~atm}$ para a formação de poros críticos, é possível elaborar o diagrama indicado na Figura 14.

Este diagrama pode ser utilizado, durante 0 processo de fabricação do aço, para verificar rapidamente se as concentrações de hidrogênio, nitrogênio, silício, carbono e oxigênio no aço podem levar à formação de porosidades, permitindo ações corretivas.

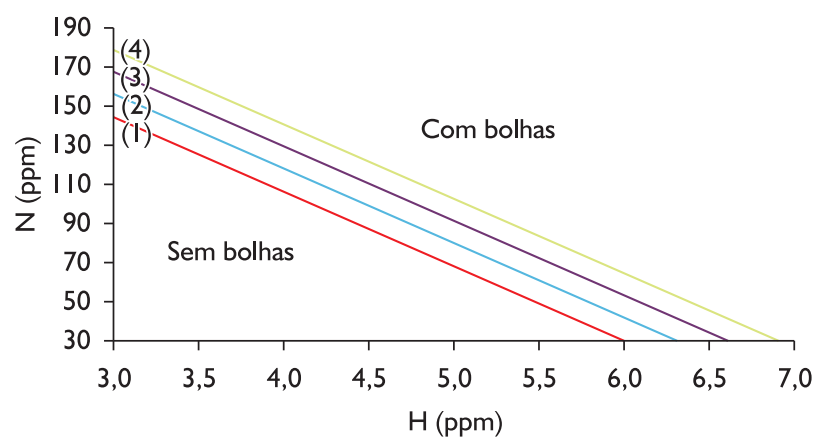

Figura 14. Diagrama de domínio crítico para formação de porosidades para aços com teores de carbono de $0,12 \%$ e $O$ de $25 \mathrm{ppm}$, sendo (I) $\mathrm{Si}=0,10 \%$, (2) $\mathrm{Si}=0,15 \%$, (3) $\mathrm{Si}=0,20 \%$, (4) $\mathrm{Si}=0,25 \%$.
Elaborando-se o diagrama para as condições I e 2 (Figura I5), nota-se que as corridas da condição I estão mais dispersas e dentro da região de aparecimento de poros críticos. O melhor desempenho das corridas da condição 2 pode ser atribuída ao menor valor de hidrogênio. Em um aço com teores de hidrogênio acima de 6 ppm há grande probabilidade de formação de poros críticos.

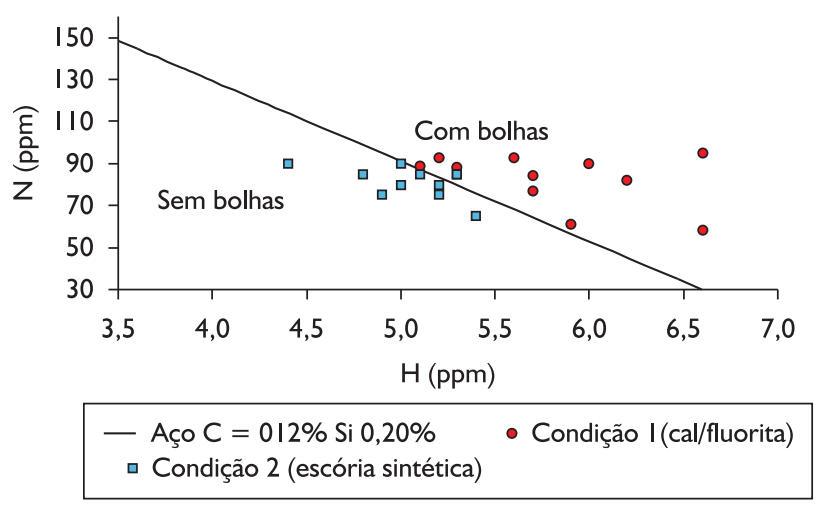

Figura I5. Diagrama de domínio crítico aplicado às condições I e 2.

\section{CONCLUSÃO}

Para a previsão de ocorrência de porosidades críticas nos tarugos, é necessário o cálculo da pressão parcial máxima dos gases $\mathrm{H}_{2}, \mathrm{~N}_{2}$ e $\mathrm{CO}$. A concentração dos elementos isoladamente não fornece uma avaliação segura. Os resultados dos cálculos das pressões dos gases, obtidos a partir do programa Thermo-Calc, são bastante satisfatórios e reproduziram adequadamente $\circ$ processo de formação de porosidades em aços. A utilização da termodinâmica computacional apresenta maior versatilidade e praticidade em relação aos modelos tradicionais de cálculo termodinâmico, principalmente no que diz respeito à possibilidade de ser aplicada a uma maior variedade de composições químicas.

Foi identificada a pressão máxima dos gases de I,2 atm como a fronteira entre corridas com e sem porosidades críticas para formação de defeitos durante a laminação. A contagem convencional do número de blow e pin holes não é um método confiável para esta previsão, apenas fornece informações qualitativas das corridas. Verifica-se que as concentrações típicas de hidrogênio, nitrogênio, oxigênio, carbono e silício dos aços longos comuns geram valores de pressão máxima muito próxima desse limite. $O$ teor de silício mostra-se um aliado na redução da pressão máxima dos gases, contribuindo para evitar a formação de porosidades. Concomitantemente com o enriquecimento do líquido em oxigênio, há uma reação de desoxidação, limitando a formação de CO.

As corridas que utilizaram escórias sintéticas sinterizadas apresentam menores valores médios e dispersão 
do teor de hidrogênio, quando comparadas com as corridas que utilizam escórias convencionais. Independentemente dos teores dos demais elementos há uma diminuição expressiva de $60 \%$ nas corridas que apresentavam $P_{\max }>1,2 \mathrm{~atm}$, reduzindo drasticamente a formação de porosidades que causam defeitos durante a laminação. A redução expressiva no sucateamento de barras laminadas confirma estes resultados.
As variações da umidade relativa do ar e da refrigeração dos eletrodos do forno elétrico não influenciam significativamente nos teores de hidrogênio do aço.

O diagrama de domínio crítico desenvolvido é uma ferramenta simples, prática e confiável, que pode ser utilizada por aciaristas durante o processo de fabricação do aço para tomar medidas que possam evitar a formação de porosidades.

\section{REFERÊNCIAS}

I VILELA, A.; BELLOC, R. Lingotamento contínuo de blocos e tarugos. São Paulo: Associação Brasileira de Metalurgia e Materiais, 2005. [Apostila].

2 ZHANG, L.; TANIGUCHI, S. Fundamentals of inclusion removal from liquid steel by attachment to rising bubbles. Iron \& Steelmaker, v. 28, n. 9, p. 55-79, 2001.

3 TURKDOGAN, E.T. Fundamentals of steelmaking. London: Institute of Materials, 1996.

4 JUNKER, T. W.; KREUSER, J. Hydrogen pickup in steel and new methods for precise hydrogen analysis. In: AISTech 2005, 2005, Charlotte, USA. Proceedings... Warrendale: Association for the Iron and Steel Technology. p. 93 I-946.

5 SCAL, M. W. Refino secundário. In: Curso Capacitação Avançada de Engenheiros. São Paulo: Gerdau, 2008.

6 HUANG, K.; LIU, Q. Blowhole formation during solidification of liquid steel. Steel Research, v. 67, n. 7, p.268-72, 1996.

7 FRUEHAN, J. The making shaping and treating of steel. I l. ed. Pittsburgh: AISE Steel Foundation, 1998.

8 TURKDOGAN, E. T. Fundamental of steelmaking. London: The Institute of Materials, 1996.

9 SCHEIL, E. Z. Über die Eutektische Kristallisation. Zeitschrift fur Metallkunde, v. 34, p. 70-2, 1942.

I0 COSTA E SILVA, A. Termodinâmica do hidrogênio no aço. In: WORKSHOP HYDROGEN IN STEEL, 5., 2007, Penedo. Disponível em: <http://equilibriumtrix.net/publications/hidrogeniol.pps> Acesso em: 20 out. 2008.

I I FRUEHAN, R. J. A review of hydrogen flaking and its prevention. Iron \& Steelmaker, v. 24, n. 8, p. 6I-9, Aug. I997.

I 2 HYDRIS application guide. Germany, 1999.

I 3 SANTOS, M. A. et al. Aplicação da escória sintética sinterizada Tecnosulfur Tecslag-Fluid 2277 à base de CaO para redução de $\mathrm{H}_{2}$ no aço durante o refino secundário. In: SEMINÁRIO DE ACIARIA INTERNACIONAL, 40., 2009, São Paulo, SP. Anais... São Paulo: ABM, 2009. p. $218-23$.

I4 HERAUS eletro-nite: Manual de operação do equipamento de medição de oxigênio solúvel (CELOX). São Paulo, 2005.

I5 KANG, Y.-B.; LEE, H.-G. Inclusions chemistry for $\mathrm{Mn} / \mathrm{Si}$ deoxidized steels: thermodynamic predictions and experimental confirmations. ISIJ International, v. 44, n. 6, p. I006-I5, 2004.

I6 SZEKELY, J.; THEMELIS, N. J. Rate phenomena in process metallurgy. New York: John Wiley, 197I. p. 60-6.

Recebido em: 26/1 I/10

Aceito em: 31/03/20I I 